\title{
Drastic reduction of orthopaedic services at an urban tertiary hospital in South Africa during COVID-19: Lessons for the future response to the pandemic
}

\author{
R Waters, ${ }^{1,2,3}$ MSc; R Dey, ${ }^{1,2,4}$ PhD; M Laubscher, ${ }^{1,2}$ MB ChB, Dip PEC (SA), FC Orth (SA), MMed (Orth); \\ R Dunn, ${ }^{1,2}$ MB ChB, FCS (SA) Orth, MMed (Orth); S Maqungo, ${ }^{\mathbf{1 , 2}}$ MB ChB, FC Orth (SA), MMed (Orth), PG Dip HPE; \\ G McCollum, ${ }^{1,2} \mathrm{MB}$ ChB, MMed (Orth), FC Orth (SA); M Nortje, , ${ }^{1,2}$ MB ChB, FC Orth (SA), MMed (Orth); \\ S Roche, ${ }^{1,2}$ MB ChB, FC Orth (SA), LMCC (Canada) (Orth); T Hilton, ${ }^{2}$ MB ChB, DA (SA), Dip PEC (SA), FC Orth (SA), MMed (Orth); \\ M Held, ${ }^{1,2} \mathrm{MD}$, MMed (Orth), FC Orth (SA), PhD, MBA \\ ${ }^{1}$ Orthopaedic Research Unit, Division of Orthopaedic Surgery, Groote Schuur Hospital, Cape Town, South Africa \\ ${ }^{2}$ Division of Orthopaedic Surgery, Groote Schuur Hospital, Cape Town, South Africa \\ ${ }^{3}$ Wellcome Centre for Infectious Disease Research in Africa (CIDRI-Africa), Institute of Infectious Disease and Molecular Medicine, \\ Faculty of Health Sciences, University of Cape Town, South Africa \\ ${ }^{4}$ Division of Biomedical Engineering, Department of Human Biology, Faculty of Healthy Sciences, University of Cape Town, South Africa
}

Corresponding author: R Waters (WTRROB005@myuct.ac.za)

\begin{abstract}
Background. The COVID-19 pandemic has impacted on the global surgery landscape.
Objectives. To analyse and describe the initial impact of the COVID-19 pandemic on orthopaedic surgery at Groote Schuur Hospital, a tertiary academic hospital in South Africa.

Methods. The number of orthopaedic surgical cases, emergency theatre patient waiting times, and numbers of outpatient clinic visits, ward admissions, bed occupancies and total inpatient days for January - April 2019 (pre-COVID-19) were compared with the same time frame in 2020 (COVID-19). The COVID-19 timeframe included initiation of a national 'hard lockdown' from 26 March 2020, in preparation for an increasing volume of COVID-19 cases.

Results. April 2020, the time of the imposed hard lockdown, was the most affected month, although the number of surgical cases had started to decrease slowly during the 3 preceding months. The total number of surgeries, outpatient visits and ward admissions decreased significantly during April 2020 (55.2\%, 69.1\% and 60.6\%, respectively) compared with April $2019(p<0.05)$. Trauma cases were reduced by 40\% in April 2020. Overall emergency theatre patient waiting time was 30\% lower for April 2020 compared with 2019.

Conclusions. COVID-19 and the associated lockdown has heavily impacted on both orthopaedic inpatient and outpatient services. Lockdown led to a larger reduction in the orthopaedic trauma burden than in international centres, but the overall reduction in surgeries, outpatient visits and hospital admissions was less. This lesser reduction was probably due to local factors, but also to a conscious decision to avoid total collapse of our surgical services.
\end{abstract}

S Afr Med J 2021;111(3):240-244. https://doi.org/10.7196/SAMJ.2021.v111i3.15263

Since COVID-19 was declared a global pandemic in March 2020, hospitals and healthcare facilities globally adapted and prepared in anticipation of a large COVID-19 burden. COVID-19, and the implemented changes, have significantly impacted on surgical practice globally, including surgical case prioritisation, SARS-CoV-2 transmission risk and mitigation strategies, especially intraoperatively and in terms of workforce and staffing issues, and changes to surgical

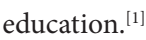

During the study period, South Africa (SA) was placed on a government-imposed level 5 'hard lockdown' from 26 March 2020. A curfew was imposed, all schools were closed, the sale of non-essentials including alcohol and cigarettes was halted, borders were closed, and quarantines were enforced on inbound travellers. The hard lockdown lasted 5 weeks, with subsequent sequential sectorial lifting. At Groote Schuur Hospital (GSH) in Cape Town, SA, non-essential surgeries and elective cases were cancelled to reduce the number of admissions and the potential in-hospital transmission of SARS-CoV-2, with a potential negative impact on orthopaedic morbidity. In addition to surgical volume changes, many of our surgeons were recruited to the front line to provide care outside their usual scope of practice. During this time, orthopaedic wards became 'COVID-19 wards' and elective orthopaedic services were cancelled. Operating theatres were divided into COVID-19 and non-COVID-19 theatres, further reducing capacity and affecting hospital surgery.

Orthopaedic services in other countries prioritised existing patients by employing stringent case selection, and also delayed noncritical surgery. As in orthopaedic units around the world, patients at GSH were screened and COVID-19 infection control measures were implemented. ${ }^{[2-6]}$ In an Italian orthopaedic centre, elective surgery declined rapidly and outpatient admissions were restricted, while emergencies increased as the hospital's orthopaedic centre became a referral unit during the COVID-19 pandemic. The same centre recorded a rapid decrease of their hip and knee arthroplasties to zero. $^{[7,8] .}$ A Greek healthcare facility recorded a significant reduction in the orthopaedic admission rate after lockdown, compared with the admission rate during the same month of the previous year. ${ }^{[9]}$ Orthopaedic healthcare services in Austria, Germany and Switzerland have suffered drastic surgical cutbacks due to COVID-19. ${ }^{[10]}$ These studies were, however, conducted in developed nations with viable and robust healthcare systems. Little is known about the effects of 
COVID-19 on orthopaedic services in a setting with limited resources.

\section{Objectives}

To describe the impact of the COVID-19 pandemic, and implemented regulations, on the orthopaedic service of a large tertiary care facility in SA.

\section{Methods}

\section{Study design and data source}

Retrospective data were extracted from a prospectively collected orthopaedic database at GSH. Patients treated at this academic hospital are mostly from lowincome households and often live in densely populated areas or informal settlements. These data were retrospectively analysed according to specific orthopaedic surgical firms, as they determine the allocation of surgeons and operating lists. As such, the number of surgeries performed for acute spinal cord injuries, foot and ankle, hand and knee cases, limb reconstruction, tumours (oncology), and elective spine, trauma and emergency, upper limb and arthroplasty cases from 1 January to 30 April 2019 (preCOVID-19) and during the same time period in 2020 (COVID-19) was collected. The 2020 data were compared with the same time period in 2019. All patients who were seen in the relevant outpatient clinics, admitted to the wards, or operated on during the study period were included. Excluded were patients aged $<13$ years, as they are treated in a paediatric hospital. Also, 39 patients in the adolescent surgery unit (25 patients in the 2019 pre-COVID-19 timeframe v. 14 patients in the 2020 COVID19 timeframe) were excluded because these numbers were low due to a recently started service and change in access to surgical lists. Data for outpatient clinic visits, patient ward admissions and inpatient days were extracted from the hospital management report and the outpatient booking system. Patient share was defined as the proportion of patients distributed among the various surgical firms in the hospital's Orthopaedic Division. It was calculated by dividing the number of patients in each surgical sector, clinical department and wards by the total number of patients in those respective firms. Bed occupancy was defined as ward beds occupied by a patient per total available ward beds. Closed wards were not seen as available beds. This bed occupancy is influenced by both bed capacity and the volume of admissions to the ward. It is a gauge for an appropriate balance between demands and available beds that allows for safe and effective patient care. Emergency theatre patient waiting times were extracted from a prospectively collected theatre database (Websurgibank) and calculated by taking into account patient entry date, patient surgery date and time of surgery. Ethical (ref. no. HREC 233/2020) and hospital institutional approval was obtained and patient confidentiality was appropriately maintained.

\section{Statistical analysis}

A preliminary power analysis using $\mathrm{G}^{\star}$ power v.3.1 $1^{[11,2]}$ showed sufficient data within the chosen timeframe to achieve excellent statistical power (1- $\beta$ ) of 0.97 . The numbers of surgeries (number of operations), outpatient visits (number of visits) and ward admissions (patient admissions, bed occupancies, total inpatient days) were compared for the year 2019 (pre-COVID-19) and 2020 (COVID-19) using the Wilcoxon test for significance. The Shapiro-Wilk test was used to assess the distribution of the data. The change in volume of admissions, visits and surgeries was described as average percentage decrease. The level of significance was set at $p<0.05$. All statistical analyses were performed in SPSS v.26 (IBM, USA).

\section{Results}

The total number of orthopaedic surgeries performed during the first quarter of 2020 decreased by $17.7 \%$ compared with the same time frame in $2019(p<0.05)$. The onset and rate of this reduction were related to the declaration of COVID-19 as a global pandemic (Fig. 1). For the first 3 months (January - March), we observed an overall decrease (between 2019 and 2020) of 4\%. The average weekly surgical volume fell significantly after week 13 , when the countrywide lockdown began at the end of March $2020(p<0.05)$ (Fig. 2). The average decrease in the month of April compared with April 2019 was $55.2 \%$. Among the various firms, upper limb, foot and ankle, and arthroplasty surgeries were drastically reduced by $100 \%$, 93.3\% and 85.7\%, respectively, in April 2020. Trauma and emergency surgeries during April 2020 were reduced by $40.4 \%$. Between firms overall this decrease was not statistically significant, with the exception of a $6.6 \%$ increase in trauma patient share in 2020 .

Emergency theatre patient waiting times were lower in 2020 compared with 2019 . The total number of completed emergency board cases decreased ( $n=272$ v. 338 ), and the largest reduction $(30 \%)$ in average waiting time (634.08 v. 443.50 minutes) was apparent in April 2020, which coincided with the rise in COVID-19 cases in SA.

Overall, outpatient clinic visits were significantly reduced $(p<0.05)$ by $26.9 \%$ in 2020 compared with 2019 (Fig. 3). Outpatient

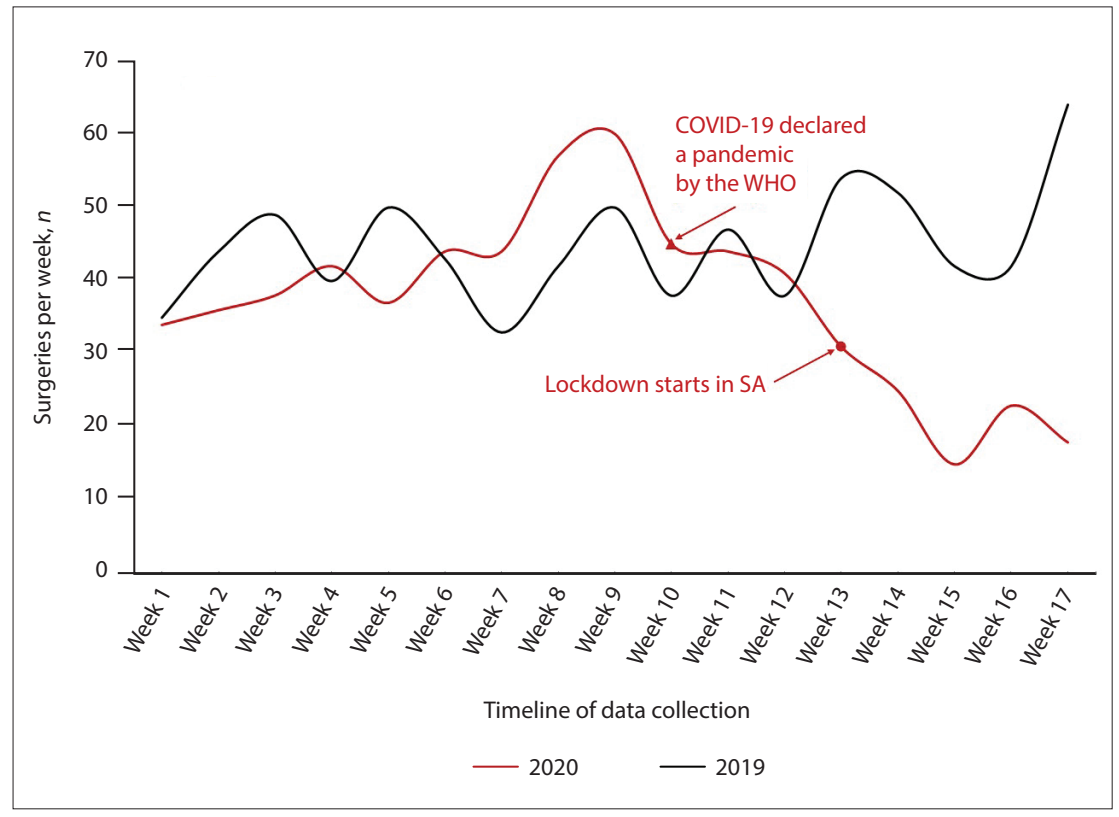

Fig. 1. Impact of COVID-19 (declared a global pandemic by the WHO on 11 March 2020) and the associated national lockdown in SA (starting on 26 March 2020) on total weekly orthopaedic surgery numbers. With level 5 lockdown, elective and non-urgent surgeries were cancelled with immediate effect. Note that a decrease in volume started prior to lockdown and change of hospital policies. Week 1 represents the first week of January and continuously progresses to week 17, representing the last week of April. $($ WHO = World Health Organization; $S A=$ South Africa.$)$ 


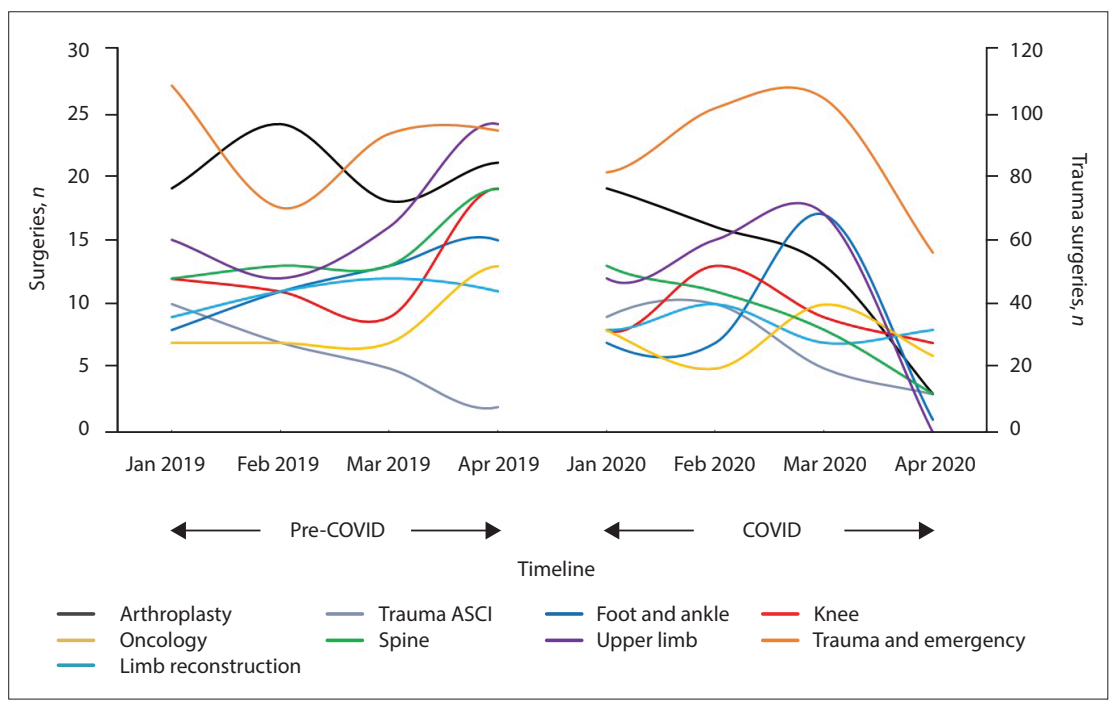

Fig. 2. Impact of COVID-19 on the number of surgeries and trauma surgeries performed in specific surgical firms in 2019 (pre-COVID-19) and 2020 (COVID-19). (Trauma ASCI = acute spinal cord injury; Spine = elective spine surgery.)

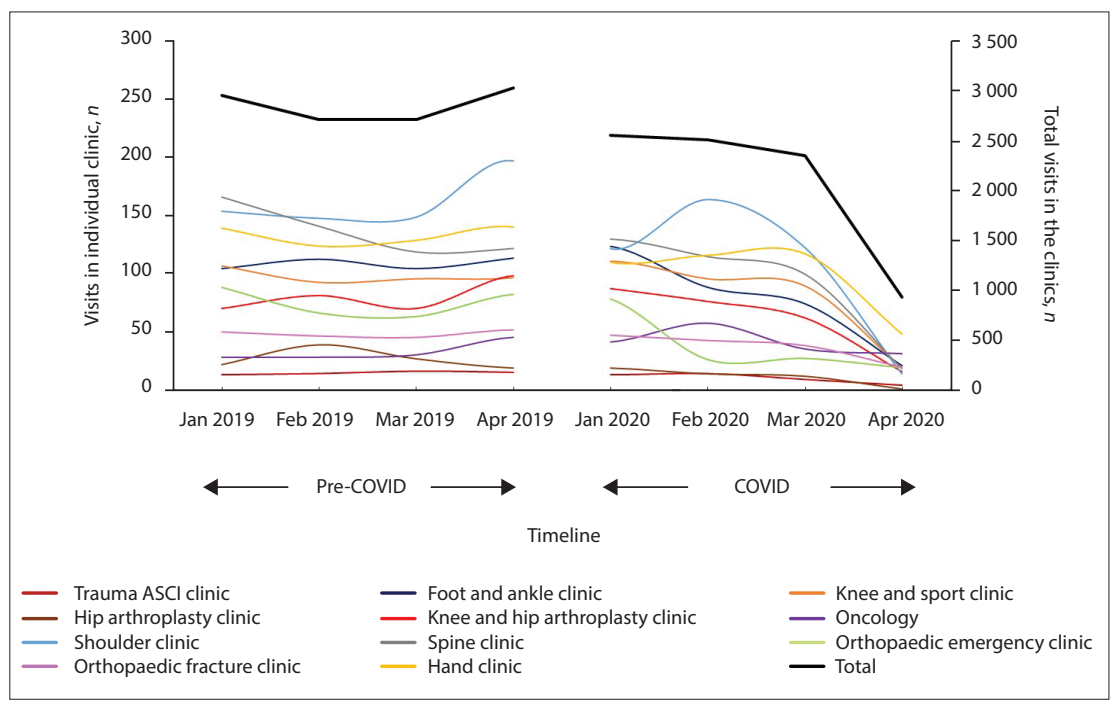

Fig. 3. Comparison of orthopaedic outpatient clinic visits in 2019 (pre-COVID-19) and 2020 (COVID-19). All orthopaedic clinics were negatively affected. Line smoothening was performed for representative purposes only. (Trauma ASCI = acute spinal cord injury; Spine = elective spine surgery.)

visit reduction was highest in the month of April $2020(p<0.05)$, with a $69.1 \%$ decrease compared with 2019. Patient visits to the hip arthroplasty, shoulder and spine clinics were affected most, with visit reductions of 94.7\% ( $p<0.05), 92.9 \%(p<0.05)$ and $85.1 \%$ $(p<0.05)$, respectively, when comparing 2019 with 2020. The various firms showed a similar reduction in volume.

We also observed that the numbers of orthopaedic surgical ward patient admissions, bed occupancies and total inpatient days were significantly lower in 2020 compared with 2019 (Fig. 4). Average ward occupancy fell by $7.5 \%$ during the first quarter of $2020(p>0.05)$. This reduction was observed for all the orthopaedic reduction in patient share was observed for the elective orthopaedic wards (occupancy, inpatient days and admissions).

\section{Discussion}

This retrospective study shows the impact of the national hard lockdown due to COVID-19, with a drastic decrease in outpatient clinical visits in April 2020 (69.1\%), followed by admissions (60.6\%), surgical volume (55.2\%) and inpatient ward bed occupancy (45.3\%). This reduction was probably due to cancellation of all elective and non-urgent surgeries, as well as the hospital's preparation for the expected COVID-19 burden. In addition, patient avoidance of hospitals, which were considered to be 'COVID-19 hotspots' and were displayed as such on social media and news platforms, further affected this reduction. ${ }^{[13-15]}$

Upon lockdown, there was a significant decrease in surgeries performed across all orthopaedic firms (55.2\%). This was primarily due to the cancellation of nonessential and elective surgical cases. Overall, this decrease was less than has been reported in other studies, ${ }^{[16]}$ as we actively decided to avoid a total collapse of surgeries during this time. Also, compared with these international centres, we may have treated more patients needing medically necessary time-sensitive surgery (MENTS), or may have assessed MENTS less selectively. However, our arthroplasty firm $(85.7 \%$ reduction) and other firms with a large volume of elective surgery showed a similar decline in numbers to a recent study in Italy (76.5\% reduction). ${ }^{[8]}$ Furthermore, trauma and emergency surgeries during April 2020 were reduced by $40.4 \%$. This echoes a similar decline of $47 \%$ in cases admitted to an emergency department in a different hospital in SA, ${ }^{[17]}$ but is higher than the $23 \%$ reduction in orthopaedic trauma surgeries found after lockdown began in Scotland. ${ }^{[18]}$ We did not change our surgical indications for trauma cases, as was done in many other parts of the world where a more conservative approach was followed. Alcohol-induced injuries, violence and general crime were reportedly reduced during lockdown in SA. ${ }^{[19-21]}$ The imposed curfew and reduced road activity also resulted in a reduction in road accidents. ${ }^{[22]}$ These factors, along with the hospital's reallocation of beds, may have been the cause for our observations of a reduction in the number of traumarelated surgeries. The volume reduction experienced may be spurious and may in 


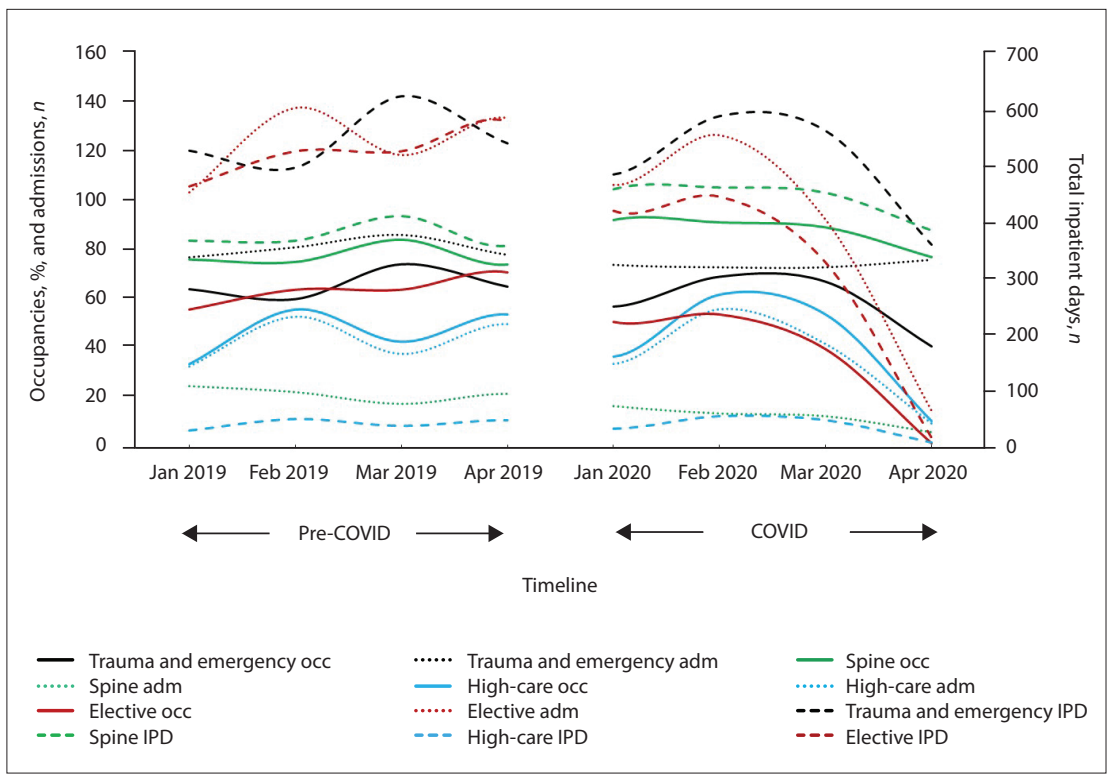

Fig. 4. Ward admissions, inpatient days, and bed occupancy comparisons for 2019 (pre-COVID-19) and 2020 (COVID-19). All were negatively affected by COVID-19 and the hard lockdown, with the exception of the spine firm. Line smoothening was performed for representative purposes only. (occ = occupancies; adm = admissions; IPD = inpatient days.)

fact be due to patients not presenting for care, which could result in a secondary future burden. A similar reduction was reported by a group of Italian general emergency surgeons, although an increase in theatre delay was found for non-traumatic emergencies because of diagnostic delays. ${ }^{[23]}$

The impact of COVID-19 on emergency theatre patient waiting time is highlighted for April 2020, the beginning of the first COVID19 peak in SA. As fewer surgical emergencies were processed during this period, there was less competition for resources, represented by a reduced waiting time to theatre. The system may well have been more adaptive as the surgeons were more available, without the usual competing elective surgical lists and due to the de-escalation of surgical activities.

The lockdown and resulting cancellation of non-urgent surgeries also led to a massive reduction in bed occupancy (45.3\%), ward admissions (60.6\%) and inpatient days (69.9\%). This decease was comparable to a study in Hong Kong, where a $41.2 \%$ reduction in hospitalisation admissions was recorded. ${ }^{[24]}$ An Italian study showed a 10.8\% reduction in trauma admissions during the first week of April, and admissions related to elective surgery decreased by up to $100 \%$. ${ }^{[25]}$ In the orthopaedic and trauma departments of a Greek hospital, the admission rate decreased by almost $90 \%{ }^{[9]}$ Some wards in our service did not follow this pattern, as certain outlets to discharge patients were not available. As such, closure of spinal rehabilitation centres led to the increase in inpatient occupancy in our spinal wards.
Furthermore, our hospital may not have experienced a similar overall burden of COVID-19 on local resources to centres described in previous studies, ${ }^{[7]}$ which left more bed availability for the orthopaedic service. The two major factors influencing bed occupancy were that bed capacity was reduced by hospital management from 117 to 60 beds to make provision for the COVID-19 wards, and that elective and nonurgent surgeries were cancelled.

After lockdown was initiated, outpatient visits decreased drastically by $69.1 \%$, which is similar to other published studies. ${ }^{[2,26]}$ Many of our patients avoided hospital care for fear of contracting COVID-19, as hospitals were depicted as 'COVID-19only' centres on the news and on social media platforms. As such, even though hospital avoidance by patients was most pronounced in April 2020, outpatient visits had already begun to decrease prior to lockdown. Although avoiding exposure to hospital-acquired COVID-19 and reduction of pressure on the orthopaedic service are obvious benefits of reducing clinical visits, they can lead to potentially devastating collateral damage. Postoperative quality of care is greatly affected by unplanned reduction of follow-up visits. Furthermore, delays in diagnosis and management of certain orthopaedic conditions can lead to permanent morbidity. ${ }^{[27]}$ Also, the additional burden of an already large number of patients awaiting elective surgery will have a devastating effect on elective surgical waiting lists. These factors need to be taken into account and weighed against potential benefits in the attempt to reduce burden on our hospitals. Policymakers should consider them when planning re-escalation of services.

\section{Study limitations}

This study has limitations. It took place in a large urban hospital in sub-Saharan Africa, and may not reflect the experience of smaller hospitals in more rural settings in Africa. However, these large hospitals are generally the major hub to process complex surgery and are often the only point of care for nontraumatic and elective procedures, which were seen to be most affected. Also time sensitivity was neither rated nor classified, although all surgery done during lockdown followed the recommendations of Prachand et $a l^{[28]}$ and excluded non-urgent elective surgery.

\section{Conclusions}

The COVID-19 hard lockdown drastically reduced the orthopaedic services at GSH. We also noted a drop in volume prior to lockdown and hospital policy changes, which points to a behavioural change, with patients avoiding hospital-related care. The backlog of both elective and non-urgent surgeries could take many months to clear and recover from.

In future studies, the re-escalation of our clinics, wards and surgery should be evaluated to understand the recovery of our service. Most importantly, we will need to evaluate the risk of contracting COVID19 during hospital visits and its associated morbidity and mortality should patients become infected. Evaluating re-escalation of our services, in conjunction with minimising COVID-19 risk, will be crucial in directing future responses to subsequent waves of the pandemic. The evaluation and planning efforts must be considered in relation to the effect on surgical waiting lists and the 'side-effects' of untreated pathology, delayed treatment and inadequate patient follow-up resulting from service restriction and hospital avoidance, which may outweigh the gains.

Declaration. The research for this study was done in partial fulfilment of the requirements for RW's $\mathrm{PhD}$ degree at the University of Cape Town.

Acknowledgements. We thank Sister Naboweya Benjamin and Sister Melody Camelo for providing us with outpatient clinic data. We also thank Dr Shrikant Peters for providing us with emergency theatre patient waiting times and insight into interpretation of the data. 
Author contributions. MH and ML conceptualised the study. RW extracted and prepared the data and wrote the manuscript. RDe performed the statistical analysis and prepared the figures. $\mathrm{MH}, \mathrm{ML}, \mathrm{RDe}, \mathrm{RDu}$ and $\mathrm{SM}$ critically revised of the manuscript. All authors read and approved the final manuscript. The manuscript was written in consultation with the UCT Ortho Authorship Group.

Funding. None.

Conflicts of interest. None.

1. Al-Jabir A, Kerwan A, Nicola M, et al. Impact of the coronavirus (COVID-19) pandemic on surgical practice - Part 1. Int J Surg 2020;79:168-179. https://doi.org/10.1016/.j.jsu.2020.05.022

2. Ding BTK, Soh T, Tan BY, et al. Operating in a pandemic: Lessons and strategies from an orthopaedic unit at the epicenter of COVID-19 in Singapore. J Bone Joint Surg 2020;102(13):e167. https://doi. org/10.2106/JBJS.20.00568

3. Iannuzzi NP, Lack WD, Gee AO, Chansky HA. An orthopaedic department's response to the COVID-19 health-care crisis: Indirect and direct actions with thoughts for the future. J Bone Joint Surg 2020;102(13):e65. https:///doi.org/10.2106/IBJS.20.00611

4. Chang Liang Z, Wang W, Murphy D, Po Hui JH. Novel coronavirus and orthopaedic surgery: Early experiences from Singapore. J Bone Joint Surg 2020;102(9):745-749. https://doi.org/10.2106/ Early experience
JBJS. 20.00236

5. Tay K, Kamarul T, Lok WY, et al. COVID-19 in Singapore and Malaysia: Rising to the challenges of orthopaedic practice in an evolving pandemic. Malays Orthop J 2020;14(2):7-15. https://doi. org/10.5704/MOJ.2007.001

6. Ducournau F, Arianni M, Awwad S, et al. COVID-19: Initial experience of an international group of hand surgeons. Hand Surg Rehabil 2020;39(3):159-166. https://doi.org/10.1016/j.hansur.2020.04.001

7. Zagra L, Faraldi M, Pregliasco F, et al. Changes of clinical activities in an orthopaedic institute in North Italy during the spread of COVID-19 pandemic: A seven-week observational analysis. Int Orthop Italy during the spread of COVID-19 pandemic: A seven-week

8. D'Apolito R, Faraldi M, Ottaiano I, et al. Disruption of arthroplasty practice in an orthopedic center in Northern Italy during the coronavirus disease 2019 pandemic. J Arthroplasty 2020;35(7S):S6-S9. https://doi.org/10.1016/j.arth.2020.04.057

9. Kenanidis E, Tsiridis E. 'Flattening the curve' of COVID-19 pandemic in orthopaedics and trauma: The Greek perspective. Injury 2020;51(7):1681-1682. https://doi.org/10.1016/j.injury.2020.05.015

10. Liebensteiner MC, Khosravi I, Hirschmann MT, Heuberer PR, Board of the AGA-Society of Arthroscopy and Joint-Surgery, Thaler M. Massive cutback in orthopaedic healthcare services due to the COVID-19 pandemic. Knee Surg Sports Traumatol Arthrosc 2020;28(6):1705-1711. https://doi. org/10.1007/s00167-020-06032-2

11. Faul F, Erdfelder E, Lang AG, Buchner A. G* Power 3: A flexible statistical power analysis program for the social, behavioral, and biomedical sciences. Behav Res Methods 2007;39(2):175-191. https://doi. org/10.3758/bf03193146

12. Faul F, Erdfelder E, Buchner A, Lang AG. Statistical power analyses using $G^{*}$ Power 3.1: Tests for correlation and regression analyses. Behav Res Methods 2009;41(4):1149-1160. https://doi. org/10.3758/BRM.41.4.1149
13. Thabye G. Concern over people with serious conditions avoiding hospitals. IOL, 17 June 2020. https://www.iol.co.za/pretoria-news/concern-over-people-with-serious-conditions-avoidinghospitals-49494068 (accessed 18 August 2020).

14. Jefferson T, Heneghan C. Hospital outbreak of COVID-19 in South Africa. Centre for Evidence-Based Medicine, 1 June 2020 (last modified 4 June). https://www.cebm.net/study/covid-19-hospital-outbreakof-covid-in-south-africa/ (accessed 18 August 2020).

of-covid-in-south-africa/ (accessed 18 August 2020).
15. Van Dyk J. Between two devils: Why hospitals must act fast to prevent health worker deaths. Bhekikisa Centre for Health Journalism, 25 May 2020. https://bhekisisa.org/health-news-south-africa/2020-05-25how-to-protect-health-workers-from-covid19/ (accessed 18 August 2020)

16. Chung WY, Winyard J, Layton GR, et al. Impact of the COVID-19 pandemic on acute adult surgical admissions - a single centre experience. Br J Surg 2020;107(10):e370-e371. https://doi.org/10.1002 bjs. 11807

17. Morris D, Rogers M, Kissmer N, et al. Impact of lockdown measures implemented during the Covid-19 pandemic on the burden of trauma presentations to a regional emergency department in Kwa-Zulu Natal, South Africa. Afr J Emerg Med 2020;10(4):193-196. https://doi.org/10.1016/j.afjem.2020.06.005

18. Jenkins P. The early effect of COVID-19 on trauma and elective orthopaedic surgery. British Orthopaedic Association, 17 April 2020. https://www.boa.ac.uk/resources/knowledge-hub/the-early-effect-of-covid19-on-trauma-and-elective-orthopaedic-surgery.html (accessed 18 August 2020).

19. Matzopoulos R, Walls H, Cook S, London L. South Africass COVID-19 alcohol sales ban: The potentia Matzopoulos R, Walls H, Cook S, London L. South Africas COVID-19 alcohol sales ban: The potential
for better policy-making. Int J Health Policy Manag 2020;9(11):486-487. https://doi.org/10.34172/ ijhpm. 2020.93

20. Isaacs L. Groote Schuur: Two-thirds drop in trauma cases due to lockdown's booze ban. Eyewitness News 2020. https://ewn.co.za/2020/04/08/groote-schuur-two-thirds-drop-in-trauma-cases-due-to-lockdowns-booze-ban (accessed 18 August 2020)

21. Movendi International. Alcohol sales ban in South Africa: Benefits and big alcohol opposition. 13 May 2020. https://movendi.ngo/news/2020/05/13/alcohol-sales-ban-in-south-africa-benefits-and-big-alcoholopposition/ (accessed 18 August 2020)

22. Davie K. Measuring the impact of the lockdown on Covid-19. Daily Maverick, 15 May 2020. https://www dailymaverick.co.za/article/2020-05-15-measuring-the-impact-of-the-lockdown-on-covid-19/ (accessed 18 August 2020).

23. Patriti A, Baiocchi GL, Catena F, Marini P, Catarci M. Emergency general surgery in Italy during the COVID-19 outbreak: First survey from the real life. World J Emerg Surg 2020;15:36. https://doi. org/10.1186/s13017-020-00314-3

24. Wong JSH, Cheung KMC. Impact of COVID-19 on orthopaedic and trauma service: An epidemiological study. J Bone Joint Surg 2020;102(14):e80. https:///doi.org/10.2106/JBSS.20.00775

25. Benazzo F, Rossi SMP, Maniscalco P, et al. The orthopaedic and traumatology scenario during Covid-19 outbreak in Italy: Chronicles of a silent war. Int Orthop 2020;44(8):1453-1459. https://doi.org/10.1007/ s00264-020-04637-3

26. Mehrotra A, Chernew M, Linetsky D, Hatch H, Cutler D. The impact of the COVID-19 pandemi on outpatient visits: A rebound emerges. The Commonwealth Fund, 19 May 2020. https://www. commonwealthfund.org/publications/2020/apr/impact-covid-19-outpatient-visits (accessed 18 August 2020).

27. Ambrosio L, Vadalà G, Russo F, Papalia R, Denaro V. The role of the orthopaedic surgeon in the COVID-1 era: Cautions and perspectives. J Exp Orthop 2020;7:35. https://doi.org/10.1186/s40634-020-00255-5

28. Prachand VN, Milner R, Angelos P, et al. Medically necessary, time-sensitive procedures: Scoring syster to ethically and efficiently manage resource scarcity and provider risk during the COVID-19 pandemic. I Am Coll Surg 2020;231(2):281-288. https://doi.org/10.1016/j.jamcollsurg.2020.04.011

Accepted 15 October 2020. 